\title{
La medicina defensiva en la práctica de la radiología
}

\author{
Cristián García B. ${ }^{1}$
}

1. Comité de Ética, Sociedad Chilena de Radiología. Santiago, Chile.

\section{¿Qué es la Medicina defensiva?}

Según el Diccionario Médico de la Universidad de Navarra, la Medicina defensiva corresponde a "El modo de ejercer la medicina que intenta evitar denuncias por mala práctica médica. Consigue este objetivo realizando un número excesivo de pruebas diagnósticas para descartar incluso situaciones insólitas, cuando ya está razonablemente claro otro diagnóstico y asegurando que el enfermo firma su consentimiento escrito a todas las pruebas o tratamientos que se le realizan".

\section{¿Puede haber algún conflicto ético involucrado?}

Sí. Claramente hay pérdida de la confianza mutua entre médico y paciente. Si nuestra práctica médica es guiada por los criterios de la medicina defensiva, las decisiones médicas no surgen del conocimiento científico o de la experiencia del médico ni persiguen un bien fundamental que es preservar la salud del paciente. Su objetivo central es protegerse ante un eventual reclamo del paciente y por lo tanto, se le considera una forma no ética de ejercicio profesional. Esto, desde que el acto médico deja de tener por objetivo central al paciente, sino proteger al propio médico.

\section{¿Es una práctica habitual?}

Desgraciadamente sí, hoy es una práctica habitual. En países desarrollados como Estados Unidos de NA y Reino Unido la mayor parte de los médicos ejerce prácticas defensivas, como referir al paciente innecesariamente, seguimientos no indicados, indicación de estudios complementarios no justificados, etc.

\section{¿Puede afectar los costos de la salud?}

Sin duda que sí. Agrega grandes costos al sistema de salud, sin justificación ni beneficios para los pacientes. Tampoco es un ejercicio profesional éticamente admisible si se lo analiza desde la perspectiva de la salud pública

\section{¿Por qué ocurre?}

Los cambios en la relación médico-paciente son universalmente reconocidos como la causa fundamental de las molestias de los pacientes y de los reclamos judiciales contra los médicos. Esto ha originado a su vez respuestas inadecuadas por parte de los médicos, dentro de los cuales la medicina defensiva es la fundamental.

Por otra parte, la medicina defensiva es ineficaz como mecanismo de prevención de los reclamos de los pacientes. De hecho, no contribuye en absoluto a lograr una relación clínica adecuada, agrega nuevos riesgos profesionales y es punto de partida de actos médicos no indicados e innecesarios.

\section{¿Es aplicable le Medicina Defensiva en Radiología?}

Sí. La práctica de la «medicina defensiva» se aplica con frecuencia en Radiología y sin duda la "Radiología defensiva" es un hecho real.

Como nuestra especialidad incluye dejar un registro escrito de nuestras opiniones o diagnósticos, estamos especialmente relacionados con la medicina defensiva.

Se nos sugiere recomendar estudios de seguimiento sobre cosas que sabemos no tendrán 
importancia, solicitar consentimiento informado para procedimientos percutáneos menores, consignar la fecha y la hora en que comunicamos un resultado crítico, hacer informes no concluyentes o ambiguos, etc. Asimismo, agregar expresiones como "no es posible descartar esto o lo otro", "no se demuestran alteraciones con esta modalidad de estudio", "se sugiere controlar", "se sugiere eventualmente solicitar exámenes complementarios". También se utilizan con frecuencia palabras como «posible», «potencial», «podría ser», «no se puede excluir». A veces podemos hacer un informe extenso y detallado, sin comprometernos realmente con ningún significado que pudiera resultar inconveniente en el caso de una demanda posterior.

Incluso cuando se está bastante seguro del diagnóstico, se utilizan términos como «sospecha de", «fuerte sospecha de» o "altamente sugerente de ".

Desgraciadamente, las motivaciones para un dictado defensivo nos distraen de nuestro objetivo que es transmitir nuestra impresión, que es finalmente lo que más le sirve al clínico para tomar una decisión y es por lo tanto importante para cuidar el bienestar del paciente. La redacción defensiva o vaga de los informes es algo que hacemos con frecuencia y el reporte es finalmente de menor utilidad para el médico que solicitó el examen y para el paciente.

También puede existir el temor de evaluación por los pares, lo que puede desembocar en un problema legal cuando una segunda opinión de un examen es utilizada como prueba

\section{¿Qué importancia tiene la Lex artis?}

La Lex Artis Medica o "estado del arte medico" es un conjunto de normas o criterios que el médico en posesión de conocimientos, habilidades y destrezas debe aplicar diligentemente en la situación concreta de un enfermo y que han sido universalmente aceptadas por sus pares.

Dada la gran variabilidad y complejidad que puede tener una condición clínica concreta, no es posible aplicar exactamente la misma normativa en todos los casos. Un buen desarrollo de la "Lex Artis medica" no solo depende del profesional, sino también del paciente, del cuadro clínico que no se ha manifestado completamente o de la relación clínica. Por eso se habla de la Lex Artis Medica ad hoc, donde el médico después de un proceso de deliberación las aplica con prudencia a la situación clínica concreta.

Para que un error médico se convierta en negligencia, se tienen que cumplir cuatro condiciones: debe existir una relación médico - paciente, un incumplimiento del deber establecido en la Lex Artis, causalidad y daño al paciente.

La mayoría de los juicios por negligencia médica que alegan un diagnóstico erróneo o faltante se refieren a un incumplimiento del deber, un incumplimiento en el estándar de atención. Esto generalmente se define como el nivel y tipo de atención que un profesional médico razonablemente competente y calificado proporcionaría en circunstancias similares a las que llevaron a la supuesta mala práctica.

En Radiología, las tasas de error en la práctica diaria varían entre 3\% y $5 \%$ y los radiólogos se encuentran entre los médicos que con mayor frecuencia están expuestos a problemas legales, por su rol central en la detección y diagnóstico de la enfermedad.

El informe radiológico constituye un documento médico - legal, es la principal forma de comunicación entre el radiólogo y el clínico y debe ser estructurado de tal manera que permita una fácil transferencia de información.

Un informe radiológico mal redactado o ambiguo puede inducir a errores en la conducta de los médicos tratantes y eventual daño al paciente. Esto también puede a su vez ser motivo de un conflicto legal.

La opinión del radiólogo debe transmitirse claramente en el informe, el que debe ser preciso y responder la duda clínica, dando consejos pertinentes si es necesario.

Siempre se considera como positivo los informes rápidos, en especial cuando hay sobrecarga de trabajo. Sin embargo, debemos revisar los informes, eliminar errores innecesarios y confirmar que es correcto el mensaje que se envía al médico tratante. 
La estrecha colaboración con nuestros colegas clínicos nos permitirá producir Informes que respondan a sus necesidades.

\section{Lectura recomendada}

1. Jha S. Teaching residents the art of defensive radiology. J Am Coll Radiol. 2004; 1: 882-884.

2. Postal E. Defensive Dictation in Radiology: A How-to Guide.
En: https://www.diagnosticimaging.com/articles/defensivedictation-radiology-how-guide

Consultado el $10 / 04 / 19$

3. Wallis A, Mc Coubrie P. The radiology report. Are we getting the message across? Clin Radiology 2011; 66: 1015-1022.

4. Rodríguez Almada $\mathrm{H}$. De la medicina defensiva a la medicina asertiva. Rev Méd Urug 2006; 22: 7-9.

5. Berlin L. Radiologic Errors and Malpractice: A Blurry Distinction. AJR 2007; 189: 517-22.

García C. La medicina defensiva en la práctica de la radiología. Rev Chil Radiol 2019; 25(1): 02-04.

*Correo electrónico: Cristián García / cgarciabruce@gmail.com 